\title{
Pembelajaran Lingkungan bagi Siswa: Hubungan Kemampuan Berpikir Kreatif dengan Kemampuan Pemecahan Masalah
}

\author{
Diana Vivanti Sigit ${ }^{1}$, Erna Heryanti ${ }^{1}$, Dyah Ayu Widya Pangestika ${ }^{1}$, Ilmi Zajuli Ichsan ${ }^{1}$ \\ ${ }^{1}$ Pendidikan Biologi-Universitas Negeri Jakarta
}

\begin{tabular}{l} 
INFO ARTIKEL \\
\hline Riwayat Artikel: \\
Diterima: $24-12-2018$ \\
Disetujui: $10-01-2019$ \\
\hline Kata kunci: \\
ability to think creatively; \\
problem solving skill; \\
environmental learning; \\
kemampuan berpikir kreatif; \\
kemampuan pemecahan masalah; \\
pembelajaran lingkungan
\end{tabular}

Alamat Korespondensi:

Diana Vivanti Sigit

Pendidikan Biologi

Universitas Negeri Jakarta

Jalan Rawamangun Muka, Jakarta Timur

E-mail: dianav@unj.ac.id

\begin{abstract}
ABSTRAK
Abstract: The ability to think creatively and problem solving is the ability that students must have in $21 \mathrm{st}$ century. The purpose of this research was to determine the relationship between creative thinking skills and students' problem solving abilities in environmental change material. The research method used is descriptive correlational method. The research was conducted at High School 4 Bekasi in semester of the 2018/2019 academic year. The sample was taken through simple random sampling technique as many as 138 students. The results showed a correlation coefficient between the ability to think creatively with students' problem solving abilities of 0.825 . The conclusion of this study is that there is a positive relationship between the ability to think creatively with students' problem solving skills.
\end{abstract}

\begin{abstract}
Abstrak: Kemampuan berpikir kreatif dan pemecahan masalah adalah kemampuan yang harus dimiliki siswa untuk menghadapi tantangan abad ke-21. Tujuan penelitian ini untuk mengetahui hubungan antara kemampuan berpikir kreatif dan kemampuan pemecahan masalah siswa pada materi perubahan lingkungan. Metode penelitian yang digunakan adalah metode deskriptif korelasional. Penelitian dilaksanakan di SMA Negeri 4 Bekasi pada semester ganjil tahun ajaran 2018/2019. Sampel diambil melalui teknik simple random sampling sebanyak 138 siswa. Hasil penelitian menunjukkan koefisien korelasi antara kemampuan berpikir kreatif dengan kemampuan pemecahan masalah siswa sebesar 0,825. Kemampuan berpikir kreatif memberikan kontribusi sebesar $68 \%$ terhadap kemampuan pemecahan masalah siswa. Kesimpulan dari penelitian ini adalah terdapat hubungan positif antara kemampuan berpikir kreatif dengan kemampuan pemecahan masalah siswa.
\end{abstract}

Saat ini pembelajaran tidak lagi mengedepankan proses menghafal konten saja, melainkan memahami masalah dan melakukan analisis terhadap permasalahan tersebut. Sudah seharusnya para pendidik memiliki peran dan tanggung jawab untuk mempersiapkan siswa dengan berbagai kemampuan berpikir agar dapat memiliki kompetensi yang dibutuhkan abad ke-21 (Anagün, 2018; Chalkiadaki, 2018; Urbani et al., 2017). Kemampuan tersebut, meliputi berpikir kreatif, berpikir kritis, pemecahan masalah, dan metakognisi (Aisyah, Salehuddin, Aman, Yasin, \& Mimiko, 2018; Callender, Franco-Watkins, \& Roberts, 2016; Song, 2016; Yeung, 2015). Kemampuan berpikir sangat penting pada abad ini sebab dibutuhkan dalam menghadapi persaingan global yang tingkat kompleksitas permasalahannya semakin tinggi di segala aspek kehidupan.

Kemampuan pemecahan masalah merupakan kemampuan yang harus dimiliki seorang siswa dalam menemukan dan mencari solusi dari sebuah permasalahan yang dia temukan.Upaya meningkatkan kemampuan pemecahan masalah siswa diperlukan kemampuan berpikir kreatif untuk mengembangkan ide atau gagasan dalam proses belajar (Azrai, Ernawati, \& Sulistianingrum, 2017; Gündüz, Alemdağ, Yaşar, \& Erdem, 2016; Weninger, 2018). Siswa yang memiliki kemampuan berpikir kreatif akan menemukan banyak cara dalam dia memecahkan solusi bagi permasalahan yang dihadapi di lingkungan sekitarnya. Hal ini sangat diperlukan dalam pembelajaran Biologi di abad 21 dikarenakan banyak sekali topik bahasan yang memerlukan kemampuan berpikir kreatif dan kemampuan pemecahan masalah (El-Hmoudova \& Milkova, 2015; Lince, 2016; Murphy, Bianchi, McCullagh, \& Kerr, 2013).

Hal ini menjelaskan bahwa tanpa kemampuan berpikir kreatif siswa akan sulit dalam mengembangkan kemampuan pemecahan masalahnya karena kurang mampu melihat berbagai alternatif solusi permasalahan. Pada kenyataannya perhatian terhadap pembentukan kemampuan berpikir kreatif belum ditangani secara sungguh-sungguh oleh para guru di sekolah. Hal ini ditunjukkan oleh hasil riset yang dilakukan Martine Prosperity Institute (2015) dalam The Global Creativity Index menyatakan 
bahwa tingkat kreativitas masyarakat Indonesia berada pada peringkat 115 dari 139 negara di dunia. Rendahnya indeks GCI mengisyaratkan bahwa pelaksanaan pembelajaran belum memenuhi tujuan pembelajaran di Indonesia dengan melahirkan kemampuan berpikir siswa. Kemampuan berpikir kreatif dan pemecahan masalah sangat dibutuhkan siswa dalam memahami konsep pelajaran terutama pada pembelajaran Biologi untuk materi lingkungan (Fauzi \& Fariantika, 2018; Gardeli et al., 2017; Markaki, 2014; Pedretti \& Nazir, 2014; Pratama, 2018).

Pada materi perubahan lingkungan banyak memunculkan masalah-masalah lingkungan yang dapat diidentifikasi serta dibutuhkan pemecahannya, sehingga dibutuhkan kemampuan pemecahan masalah yang baik. Permasalahan yang muncul misalkan saja mengenai sampah, polusi, dan hilangnya hutan dan tak kalah pentingnya adalah masalah konsumsi yang ramah lingkungan (Arnold, Kibbe, Hartig, \& Kaiser, 2018; Ichsan, Sigit, Miarsyah, Azrai, \& Heryanti, 2019; Nam, Dong, \& Lee, 2017; Sangroya \& Nayak, 2017). Hal tersebut menjadi kajian penting bagi siswa. Hal ini dikarenakan keterlibatan kemampuan berpikir kreatif diduga akan membantu siswa meningkatkan kemampuan pemecahan masalahnya dalam mengatasi masalah perubahan lingkungan (Bronfman, Cisternas, López-Vázquez, De la Maza, \& Oyanedel, 2015; Pedretti \& Nazir, 2014; Şener, Türk, \& Taş, 2015; Widiana, Jampel, \& Jampel, 2016; Wiener-Ogilvie, Bennison, \& Smith, 2014). Berdasarkan permasalahan di atas maka perlu dilakukan penelitian dengan tujuan untuk mengetahui hubungan antara kemampuan berpikir kreatif dan kemampuan pemecahan masalah siswa pada materi perubahan lingkungan.

\section{METODE}

Metode penelitian yang digunakan adalah metode kuantitatif dengan studi deskriptif korelasional. Penelitian dilaksanakan di SMA Negeri 4 Bekasi pada semester ganjil tahun ajaran 2018/2019. Populasi target dalam penelitian adalah seluruh siswa di SMA Negeri 4 Kota Bekasi. Populasi terjangkau diambil menggunakan teknik purposive sampling, yaitu siswa kelas XI SMAN 4 Kota Bekasi. Sampel diambil melalui teknik simple random sampling menggunakan rumus Slovin sehingga diperoleh 138 dari 211 siswa. Teknik pengumpulan data dalam penelitian ini berupa tes kemampuan berpikir kreatif dan tes kemampuan pemecahan masalah dalam bentuk soal uraian pada materi perubahan lingkungan. Instrumen kemampuan berpikir kreatif diadaptasi dari Munandar, (2012) dan instrumen kemampuan pemecahan masalah diadaptasi dari Nitko \& Brookhart (2011). Adapun aspek-aspek dari berbagai instrument yang digunakan dapat dilihat pada Tabel 1. Analisis data yang digunakan adalah dengan uji korelasi, sebelumnya dilakukan uji pendahuluan yaitu uji normalitas dan homogenitas.

Tabel 1. Aspek kemampuan Berpikir kreatif dan Kemampuan Pemecahan Masalah

\begin{tabular}{lll}
\hline No & Aspek Kemampuan Berpikir Kreatif & Aspek Kemampuan Pemecahan Masalah \\
\hline 1 & Kelancaran (fluency) & Mengidentifikasi masalah \\
2 & Keluwesan (flexibility) & Menentukan tujuan \\
3 & Keaslian (originality) & Mengeksplorasi strategi \\
4 & Keterperincian (elaboration) & Melaksanakan strategi \\
\hline
\end{tabular}

\section{HASIL}

Berdasarkan hasil tes kemampuan berpikir kreatif yang diberikan kepada siswa, menunjukkan nilai kemampuan berpikir kreatif tertinggi siswa adalah 89 dan nilai terendah adalah 36 dengan rata-rata nilai 62,49. Frekuensi jumlah siswa terbanyak berada pada rentang nilai 65,5-72,5 sebanyak 41 siswa $(29,7 \%)$ dan frekuensi jumlah siswa paling sedikit berada pada rentang nilai 85,5-92,5 sebanyak 1 siswa $(0,7 \%)$. Berdasarkan kriteria nilai kemampuan berpikir kreatif siswa, terdapat lima siswa (3\%) dengan kriteria sangat tinggi, sebanyak 79 siswa (58\%) dengan kriteria tinggi, sebanyak 51 siswa (37\%) dengan kriteria sedang, dan sebanyak tiga siswa (2\%) dengan kriteria rendah. Kemampuan berpikir kreatif digambarkan berdasarkan aspek kemampuan berpikir kreatif yang dapat dilihat pada Tabel 2 dan 3. Persentase tertinggi diperoleh pada aspek kelancaran (fluency) yaitu sebesar 28\%, diikuti pada aspek keluwesan (flexibility) $25 \%$, aspek keaslian (originality) $24 \%$, dan aspek keterperincian (elaboration) $23 \%$.

Berdasarkan hasil tes kemampuan pemecahan masalah yang diberikan kepada siswa, menunjukkan nilai kemampuan pemecahan masalah tertinggi siswa adalah 95 dan nilai terendah adalah 35 dengan rata-rata nilai 65,11 . Frekuensi jumlah siswa terbanyak berada pada rentang nilai 66,5 - 74,5 sebanyak 35 siswa $(25,4 \%)$ dan frekuensi jumlah siswa paling sedikit berada pada rentang nilai 89,5-97,5 sebanyak dua siswa (1,4\%). Berdasarkan kriteria nilai kemampuan pemecahan masalah siswa, terdapat 17 siswa (12\%) dengan kriteria sangat tinggi, sebanyak 68 siswa (49\%) dengan kriteria tinggi, sebanyak 49 siswa (36\%) dengan kriteria sedang, dan sebanyak empat siswa (3\%) dengan kriteria rendah. Kemampuan pemecahan masalah digambarkan berdasarkan aspek kemampuan pemecahan masalah yang dapat dilihat pada Tabel 4 dan 5. Persentase tertinggi diperoleh pada aspek mengidentifikasi masalah yaitu sebesar 22\%, sedangkan persentase terendah diperoleh pada aspek mengkaji dan mengevaluasi kembali, yakni sebesar $17 \%$ 
Tabel 2. Distribusi Frekuensi Nilai Kemampuan Berpikir Kreatif Siswa

\begin{tabular}{cccccc}
\hline No. & Kelas Interval & Batas Bawah & Batas Atas & $\begin{array}{c}\text { Frekuensi } \\
\text { Absolut }\end{array}$ & Frekuensi Relatif $(\%)$ \\
\hline 1 & $36-43$ & 35,5 & 43,5 & 5 & 3,6 \\
2 & $44-51$ & 43,5 & 51,5 & 13 & 9,4 \\
3 & $52-58$ & 51,5 & 58,5 & 36 & 26,1 \\
4 & $59-65$ & 58,5 & 65,5 & 23 & 16,7 \\
5 & $66-72$ & 65,5 & 72,5 & 41 & 29,7 \\
6 & $73-79$ & 72,5 & 79,5 & 15 & 10,9 \\
7 & $80-86$ & 79,5 & 86,5 & 4 & 2,9 \\
8 & $86-92$ & 85,5 & 92,5 & 1 & 0,7 \\
\hline
\end{tabular}

Tabel 3. Skor Kemampuan Berpikir Kreatif Siswa per Aspek

\begin{tabular}{clc}
\hline No & Aspek Kemampuan Berpikir Kreatif & Persentase (\%) \\
\hline 1 & Kelancaran (fluency) & 28 \\
2 & Keluwesan (flexibility) & 25 \\
3 & Keaslian (originality) & 24 \\
4 & Keterperincian (elaboration) & 23 \\
\hline
\end{tabular}

Tabel 4. Distribusi Frekuensi Nilai Kemampuan Pemecahan Masalah Siswa

\begin{tabular}{cccccc}
\hline No. & Kelas Interval & Batas Bawah & Batas Atas & $\begin{array}{c}\text { Frekuensi } \\
\text { Absolut }\end{array}$ & Frekuensi Relatif (\%) \\
\hline 1 & $35-42$ & 34,5 & 42,5 & 4 & 2,9 \\
2 & $43-50$ & 42,5 & 50,5 & 11 & 8,0 \\
3 & $51-58$ & 50,5 & 58,5 & 29 & 21,0 \\
4 & $59-66$ & 58,5 & 66,5 & 28 & 20,3 \\
5 & $67-74$ & 66,5 & 74,5 & 35 & 14,4 \\
6 & $75-82$ & 74,5 & 82,5 & 20 & 6,5 \\
7 & $83-89$ & 82,5 & 89,5 & 9 & 1,4 \\
8 & $90-97$ & 89,5 & 97,5 & 2 & \\
\hline
\end{tabular}

Tabel 5. Skor Kemampuan Pemecahan Masalah Siswa per Aspek

\begin{tabular}{llc}
\hline No & Aspek Kemampuan Pemecahan Masalah & Persentase (\%) \\
\hline 1 & Mengidentifikasi masalah & 22 \\
2 & Menentukan tujuan & 21 \\
3 & Mengeksplorasi strategi & 21 \\
4 & Melaksanakan strategi & 20 \\
5 & Mengkaji dan mengevaluasi kembali & 17 \\
\hline
\end{tabular}

Hasil penelitian menunjukkan koefisien korelasi antara kemampuan berpikir kreatif dengan kemampuan pemecahan masalah siswa sebesar 0,825 pada persamaan model regresi $\hat{Y}=7,527+0,924 \mathrm{X}$. Hasil perhitungan hubungan antara kemampuan berpikir kreatif dengan kemampuan pemecahan masalah diperoleh nilai koefisien korelasi ( $\mathrm{r}_{\mathrm{xy}}$ ) $\mathrm{sebesar} 0,825$ yang berarti terdapat hubungan yang tinggi antara kemampuan berpikir kreatif dengan kemampuan pemecahan masalah. Koefisien determinasi $\left(\mathrm{r}_{\mathrm{xy}}\right)^{2}$ yang diperoleh adalah 0,680 . Berdasarkan hasil perhitungan diperoleh besarnya kontribusi variabel $\mathrm{X}$ terhadap variabel $\mathrm{Y}\left(\mathrm{r}^{2}\right.$ x $\left.100 \%\right)$ adalah $68 \%$. Hal tersebut menunjukkan bahwa kemampuan berpikir kreatif memberikan kontribusi sebesar $68 \%$ dalam menentukan kemampuan pemecahan masalah siswa.

Tabel 6. Hubungan antara Kemampuan Berpikir Kreatif dan Kemampuan Pemecahan Masalah pada Materi Perubahan Lingkungan

\begin{tabular}{llll}
\hline Korelasi & $\mathbf{r}_{\mathrm{xy}}$ & $\mathbf{r}_{\mathrm{xy}}{ }^{2}$ & Sig. \\
\hline $\mathrm{X} \rightarrow \mathrm{Y}$ & $0,825^{*}$ & 0,680 & 0,000 \\
\hline
\end{tabular}

*Taraf signifikan pada $\alpha=0,05$ 
Berdasarkan hasil penelitian diperoleh nilai rata-rata kemampuan berpikir kreatif adalah 62,48 yang termasuk dalam kategori tinggi. Persentase siswa dengan kemampuan berpikir kreatif sangat tinggi sebesar 3\%, tinggi sebesar 57\%, sedang 37\%, dan rendah sebesar 2\%. Meskipun rata-rata nilai keseluruhan sampel tergolong tinggi dan nilai tertinggi sebesar 89 , namun masih terdapat nilai sangat rendah yang didapatkan siswa yaitu sebesar 36. Perolehan nilai tertinggi dan terendah menunjukkan adanya ketimpangan nilai yang diperoleh siswa.

\section{PEMBAHASAN}

Perbedaan tinggi rendahnya nilai tersebut dapat menjadi gambaran kemampuan berpikir kreatif yang masih belum sepenuhnya optimal. Hal tersebut juga menunjukkan bahwa tidak terdapat siswa yang sama sekali tidak memiliki kemampuan kemampuan berpikir kreatif. Hal ini dikarenakan kemampuan berfikir kreatif siswa disebabkan oleh banyak faktor dan kebiasaan. Pembelajaran lingkungan di sekolah juga turut serta memengaruhi besar dan kecilnya kemampuan berpikir siswa (Latta, Hanson, Ragoonaden, Briggs, \& Middleton, 2017; Miller, 2018; Şener et al., 2015; Song, 2016; Wall, 2015). Siswa yang memiliki kemampuan berpikir kreatif rendah antara lain disebabkan karena keterbatasan akses dan informasi untuk mendapatkan banyak informasi yang banyak sehingga dapat merangsang kemampuannya dalam berkreativitas (Khuana, Khuana, \& Santiboon, 2017; Tanujaya, Mumu, \& Margono, 2017).

Siswa yang mampu memecahkan masalah dengan baik dapat mengidentifikasi permasalahan, menentukan tujuan dengan merumuskan permasalahan, mengeksplorasi berbagai strategi, dan mengkaji serta mengevaluasi kembali hingga dapat menentukan solusi yang paling tepat untuk sebuah permasalahan. Hasil penelitian menunjukkan bahwa aspek mengidentifikasi masalah memiliki persentase skor paling tinggi dibandingkan dengan aspek lain yakni $22 \%$. Hal ini ditandai bahwa siswa telah mampu mengidentifikasi masalah dengan baik yaitu dapat menyebutkan beberapa pokok permasalahan yang ada dalam soal. Keterampilan mengidentifikasi masalah adalah kemampuan yang sangat penting dalam mempelajari topik-topik lingkungan (Aguilar-Salinas, Ojeda-Benitez, Cruz-Sotelo, \& Castro-Rodríguez, 2017; Okur-Berbeglu, 2015; Truelove \& Gillis, 2018).

Aspek mengkaji dan mengevaluasi kembali jawaban merupakan aspek dengan persentase terendah yakni 17\%. Data ini menunjukkan bahwa siswa masih kesulitan dalam memilih salah satu alternatif sebagai solusi terbaik dan menjadikannya sebuah langkah yang nyata. Keterampilan siswa dalam melakukan penilaian terhadap suatu kasus termasuk kemampuan yang diperlukan dalam pembelajaran abad 21. Kemampuan ini dapat dilatih dengan membiasakan diri untuk berfikir analitis dan kritis. Guru juga memiliki peran dalam mempersiapkan berbagai model, media, dan perangkat pembelajaran untuk meningkatkan kemampuan siswa dalam mengevaluasi (Chang, Liang, Chou, \& Lin, 2017; Gündüz et al., 2016; Ramdhani \& Muhammadiyah, 2015; Suhendar \& Wahyuni, 2018; Wall, 2015).

Secara keseluruhan, hasil penelitian menunjukkan menunjukkan bahwa terdapat hubungan antara kemampuan berpikir kreatif dengan kemampuan pemecahan masalah termasuk dalam kriteria yang tinggi. Besarnya nilai kontribusi menunjukkan bahwa kemampuan berpikir kreatif memberikan pengaruh yang dominan terhadap kemampuan pemecahan masalah. Hal ini menjadi fokus diskusi di kalangan para guru agar dapat meningkatkan kemampuan siswa tersebut. Hal itu dikarenakan siswa yang memiliki kemampuan berpikir kreatif tinggi, maka akan membantu dirinya untuk memecahkan masalah (Jensen, McDaniel, Woodard, \& Kummer, 2014; Vijayaratnam, 2012; Yang, 2018).

Hasil nilai kemampuan berpikir kreatif dan kemampuan pemecahan masalah yang belum optimal ini dikarenakan siswa tidak terbiasa dilatih untuk melakukan pemecahan masalah dan mencari solusi-solusi alternatif lain. Kemampuan ini tidak bersifat tetap, artinya kemampuan dalam diri siswa dapat dikembangkan. Pembelajaran dapat dikembangkan dengan melakukan penyesuaian dan pengembangan. Guru dapat mengembangkan media yang dapat merangsang kemampuan siswa agar pembelajaran lebih bermakna. Pengembangan media dapat dilakukan oleh guru dengan menggunakan website yang bersifat daring sehingga siswa dapat mengakses informasi dan pembelajaran dapat berlangsung dimana saja (Fatih, 2016; Fitriani, Adisyahputra, \& Komala, 2018; Ho \& Yao, 2018; Jung, 2015; Unal \& Karakuş, 2016). Penyesuaian juga dapat dilakukan dengan melakukan inovasi-inovasi model dan metode pembelajaran. Karakteristik model dan metode yang digunakan haruslah yang dapat mendukung meniningkatnya kreativitas siswa dan daya analitis siswa.

Pada pembelajaran lingkungan, siswa dapat diberikan tugas untuk melakukan analisis permasalahan kemudian ditugaskan membuat karya dari sisa bahan bekas menjadi sebuah produk yang bermanfaat (Ichsan \& Mulyani, 2018; Paddison \& Mortimer, 2016; Vidergor \& Krupnik-Gottlieb, 2015). Hal ini akan mendorong kreativitas siswa dalam mendesain suatu produk dan nantinya akan berdampak pada perubahan kebiasaan siswa tersebut dalam menjaga lingkungan. Hal ini dikarenakan perubahan perilaku siswa dapat terjadi karena perlakuan yang diberikan dalam pembelajaran (Ichsan, Sigit, \& Miarsyah, 2018; Spinola, 2015; Vicente-Molina, Fernández-Sainz, \& Izagirre-Olaizola, 2018).

Guru juga dapat menggunakan paltform media sosial untuk pembelajaran. Hal ini sangat membantu guru dalam menyampaikan konsep-konsep lingkungan yang belum sempat terjawab di kelas. Penggunaan media sosial dalam pembelajaran sangat membantu dikarenakan banyak siswa yang menggunakannya. Pembelajaran juga terkesan lebih hidup dan tidak kaku seperti di dalam kelas, siswa dapat mengakses informasi dari berbagai sumber digital (Evans, 2014; Farisi, 2016; Juhanda \& Maryanto, 2018; Yusop \& Sumari, 2013; Zhou, Lee, \& Sin, 2017). Hal ini sangat berdampak pada aktifnya siswa dalam 
pembelajaran. Siswa yang aktif dalam pembelajaran cenderung akan memudahkan guru dalam menyampaikan permasalahan lingkungan dan konsep lingkungan (Hyun, Ediger, \& Lee, 2017; Lile \& Bran, 2014; Owens, Sadler, Barlow, \& Smith-Walters, 2017).

\section{SIMPULAN}

Hasil menunjukkan bahwa kemampuan berpikir kreatif dan kemampuan pemecahan masalah siswa berada pada kategori tinggi. Terdapat hubungan positif antara kemampuan berpikir kreatif dengan kemampuan pemecahan masalah siswa pada materi perubahan lingkungan. Siswa yang memiliki kriteria kemampuan berpikir kreatif dan pemecahan masalah yang rendah sebaiknya berupaya untuk meningkatkan kemampuannya sehingga dapat menyelesaikan permasalahan dengan baik. Guru diharapkan mampu menyediakan situasi belajar yang menunjang agar kemampuan berpikir kreatif dan kemampuan pemecahan masalah siswa dapat berkembang. Penelitian lebih lanjut harus dilakukan. Hal ini dikarenakan dalam penelitian ini hanya menhitung besar korelasi dari kedua variabel. Penelitian lainnya hendaknya membahas tentang pengaruh model, media, dan metode pembelajaran terhadap kreativitas siswa dan kemampuan siswa dalam memecahkan masalah.

\section{DAFTAR RUJUKAN}

Aguilar-Salinas, W., Ojeda-Benitez, S., Cruz-Sotelo, S., \& Castro-Rodríguez, J. (2017). Model to Evaluate Pro-Environmental Consumer Practices. Environments, 4(1), 11. https://doi.org/10.3390/environments4010011

Aisyah, A., Salehuddin, K., Aman, I., Yasin, R. ., \& Mimiko, N. (2018). Eliciting Elements of Higher Order Thinking Skills in the Higher Secondary Examination Question Structure in Japan and Malaysia Aznur. In Proceedings of the Regional Conference on Science, Technology and Social Sciences (RCSTSS 2016) (pp. 455-464). Springer Singapore. https://doi.org/10.1007/978-981-13-0074-5

Anagün, Ş. S. (2018). Teachers' Perceptions about the Relationship between 21st Century Skills and Managing Constructivist Learning Environments. International Journal of Instruction, 11(4), 825-840. https://doi.org/10.12973/iji.2018.11452a

Arnold, O., Kibbe, A., Hartig, T., \& Kaiser, F. G. (2018). Capturing the Environmental Impact of Individual Lifestyles: Evidence of the Criterion Validity of the General Ecological Behavior Scale. Environment and Behavior, 50(3), 350-372. https://doi.org/10.1177/0013916517701796

Azrai, E. P., Ernawati, E., \& Sulistianingrum, G. (2017). Pengaruh Gaya Belajar David Kolb (Divergen, Assimilator, Convergen, Accommodator) Terhadap Hasil Belajar Siswa Pada Materi Pencemaran Lingkaran. Biosfer: Jurnal Pendidikan Biologi, 10(1), 9-16. https://doi.org/https://doi.org/10.21009/biosferjpb.10-1.2

Bronfman, N. C., Cisternas, P. C., López-Vázquez, E., De la Maza, C., \& Oyanedel, J. C. (2015). Understanding attitudes and pro-environmental behaviors in a Chilean community. Sustainability, 7(10), 14133-14152. https://doi.org/10.3390/su71014133

Callender, A. A., Franco-Watkins, A. M., \& Roberts, A. S. (2016). Improving metacognition in the classroom through instruction, training, and feedback. Metacognition and Learning, 11(2), 215-235.

Chalkiadaki, A. (2018). A Systematic Literature Review of 21st Century Skills and Competencies in Primary Education. International Journal of Instruction, 11(3), 1-16. https://doi.org/10.12973/iji.2018.1131a

Chang, C. C., Liang, C., Chou, P. N., \& Lin, G. Y. (2017). Is game-based learning better in flow experience and various types of cognitive load than non-game-based learning? Perspective from multimedia and media richness. Computers in Human Behavior, 71, 218-227. https://doi.org/10.1016/j.chb.2017.01.031

El-Hmoudova, D., \& Milkova, E. (2015). Variations and Frequencies in Learning Styles in a Group of Czech English as Foreign Language Learners. Procedia - Social and Behavioral Sciences, 182, 60-66. https://doi.org/10.1016/j.sbspro.2015.04.738

Evans, C. (2014). Twitter for teaching: Can Social Media be Used to Enhance The Process of Learning? British Journal of Educational Technology, 45(5), 902-915. https://doi.org/10.1111/bjet.12099

Farisi, M. I. (2016). Developing the 21 st-century social studies skills through technology integration. Turkish Online Journal of Distance Education-TOJDE, 17(1), 16-30. https://doi.org/10.17718/tojde.47374

Fatih, M. T. uuml rker. (2016). Design process for online websites created for teaching Turkish as a foreign language in web based environments. Educational Research and Reviews, 11(8), 642-655. https://doi.org/10.5897/ERR2015.2511

Fauzi, A., \& Fariantika, A. (2018). Courses perceived difficult by undergraduate students majoring in biology. Biosfer: Jurnal Pendidikan Biologi, 11(2), 78-89. https://doi.org/https://doi.org/10.21009/biosferjpb.v11n2.78-89

Fitriani, U., Adisyahputra, A., \& Komala, R. (2018). Eco-friendly website development in biology learning based on project activities on environmental pollution. Biosfer: Jurnal Pendidikan Biologi, 11(1), 32-46. https://doi.org/https://doi.org/10.21009/biosferjpb.11-1.4 
Gardeli, A., Vosinakis, S., Englezos, K., Mavroudi, D., Stratis, M., \& Stavrakis, M. (2017). Design and Development of Games and Interactive Installations for Environmental Awareness. EAI Endorsed Transactions on Game-Based Learning, 4(12), 1-11. https://doi.org/10.4108/eai.8-12-2017.153402

Gündüz, A. Y., Alemdağ, E., Yaşar, S., \& Erdem, M. (2016). Design of a Problem-Based Online Learning Environment and Evaluation of its Effectiveness. The Turkish Online Journal of Educational Technology, 15(3), 49-57. https://doi.org/10.1017/CBO9781107415324.004

Ho, J. C. F., \& Yao, M. Z. (2018). Encouraging Learners to Explore Websites: Hyperlinks as Invitations. Journal of Educators Online, 15(2). https://doi.org/10.9743/jeo.2018.15.2.4

Hyun, J., Ediger, R., \& Lee, D. (2017). Students' Satisfaction on Their Learning Process in Active Learning and Traditional Classrooms. International Journal of Teaching, 29(1), 108-118. Retrieved from http://www.isetl.org/ijtlhe/

Ichsan, I. Z., \& Mulyani, S. W. W. (2018). Improving Students' Motoric Skills Through Demonstration Method in Recycling Plastic Waste. JPBI (Jurnal Pendidikan Biologi Indonesia), 4(2), 189-194. https://doi.org/10.22219/jpbi.v4i2.5890

Ichsan, I. Z., Sigit, D. V., \& Miarsyah, M. (2018). Learning Environment: Gender Profile of Students' Pro-Environmental Behavior (PEB) based on Green Consumerism. Tadris: Jurnal Keguruan Dan Ilmu Tarbiyah, 3(2), 97-107. https://doi.org/10.24042/tadris.v3i2.3358

Ichsan, I. Z., Sigit, D. V., Miarsyah, M., Azrai, E. P., \& Heryanti, E. (2019). Students' pro-environmental behavior and environmental learning outcomes based on green consumerism. JPBI (Jurnal Pendidikan Biologi Indonesia), 5(1).

Jensen, J. L., McDaniel, M. A., Woodard, S. M., \& Kummer, T. A. (2014). Teaching to the Test...or Testing to Teach: Exams Requiring Higher Order Thinking Skills Encourage Greater Conceptual Understanding. Educational Psychology Review, 26(2), 307-329. https://doi.org/10.1007/s10648-013-9248-9

Juhanda, A., \& Maryanto, Y. (2018). The emergence of biological problems in electronic school books (bse) class x reviewed from the scientific knowledge domain of scientific literacy. Biosfer: Jurnal Pendidikan Biologi, 11(2), 121-125. https://doi.org/https://doi.org/10.21009/biosferjpb.v11n2.121-125

Jung, J. (2015). A study on the effects of the rubric on concurrent discussion in web-based environment. In Proceedings of the 12th International Conference on Cognition and Exploratory Learning in the Digital Age, CELDA 2015 (pp. 319-322). Retrieved from https://www.scopus.com/inward/record.uri?eid=2-s2.084961783299\&partnerID=40\&md5=242561e93ca57e19501a5ccdc712ff7f

Khuana, K., Khuana, T., \& Santiboon, T. (2017). An instructional design model with the cultivating research-based learning strategies for fostering teacher students creative thinking abilities. Educational Research and Reviews, 12(15), 712-724. https://doi.org/10.5897/ERR2017.3239

Latta, M. M., Hanson, K., Ragoonaden, K., Briggs, W., \& Middleton, T. (2017). Accessing the curricular play of critical and creative thinking. Canadian Journal of Education, 40(3), 191-218.

Lile, R., \& Bran, C. (2014). The Assessment of Learning Outcomes. Procedia - Social and Behavioral Sciences, $163,125-131$. https://doi.org/10.1016/j.sbspro.2014.12.297

Lince, R. (2016). Creative Thinking Ability to Increase Student Mathematical of Junior High School by Applying Models Numbered Heads Together. Journal of Education and Practice, 7(6), 206-212.

Markaki, V. (2014). Environmental Education through Inquiry and Technology. Science Education International, $25(1), 86-92$.

Miller, A. L. (2018). The Role of Creative Coursework in Skill Development for University Seniors. Global Education Review, 5(1), 88-107.

Murphy, C., Bianchi, L., McCullagh, J., \& Kerr, K. (2013). Scaling up higher order thinking skills and personal capabilities in primary science: Theory-into-policy-into-practice. Thinking Skills and Creativity, 10, 173-188. https://doi.org/10.1016/j.tsc.2013.06.005

Nam, C., Dong, H., \& Lee, Y. A. (2017). Factors influencing consumers' purchase intention of green sportswear. Fashion and Textiles, 4(2), 1-17. https://doi.org/10.1186/s40691-017-0091-3

Nitko, A. J., \& Brookhart, S. M. (2011). Educational assesment of students. Columbus: Pearson Education.

Okur-Berbeglu, E. (2015). The Effect of Ecopodagogy-Based Environmental Education on Environmental Attitude of Inservice Teachers. International Electronic Journal of Environmental Education, 5(2), 86-110. https://doi.org/10.18497/iejee-green.09988

Owens, D. C., Sadler, T. D., Barlow, A. T., \& Smith-Walters, C. (2017). Student Motivation from and Resistance to Active Learning Rooted in Essential Science Practices. Research in Science Education, 1-25. https://doi.org/10.1007/s11165017-9688-1

Paddison, B., \& Mortimer, C. (2016). Authenticating the learning environment. Journal of Teaching in Travel and Tourism, 16(4), 331-350. https://doi.org/10.1080/15313220.2016.1245121

Pedretti, E., \& Nazir, J. (2014). Tensions and opportunities: A baseline study of teachers' views of environmental education. International Journal of Environmental and Science Education, 9(3), 265-283. https://doi.org/10.12973/ijese.2014.215a 
Pratama, A. T. (2018). Improving metacognitive skills using problem based learning (pbl) at natural science of primary school in deli serdang, indonesia. Biosfer: Jurnal Pendidikan Biologi, 11(2), 101-107. https://doi.org/https://doi.org/10.21009/biosferjpb.v11n2.101-107

Ramdhani, M. A., \& Muhammadiyah, H. (2015). The Criteria of Learning Media Selection for Character Education in Higher Education. International Conference of Islamic Educatios in Shoutheast Asia, (March), 1-9.

Sangroya, D., \& Nayak, J. K. (2017). Factors influencing buying behaviour of green energy consumer. Journal of Cleaner Production, 151, 393-405. https://doi.org/10.1016/j.jclepro.2017.03.010

Şener, N., Türk, C., \& Taş, E. (2015). Improving Science Attitude and Creative Thinking through Science Education Project: A Design, Implementation and Assessment. Journal of Education and Training Studies, 3(4), 57-67. https://doi.org/10.11114/jets.v3i4.771

Song, X. (2016). "Critical Thinking” and Pedagogical Implications for Higher Education. East Asia, 33(1), 25-40. https://doi.org/10.1007/s12140-015-9250-6

Spinola, H. (2015). Environmental literacy comparison between students taught in Eco-schools and ordinary schools in the Madeira Island region of Portugal. Science Education International, 26(3), 392-413.

Suhendar, S., \& Wahyuni, A. (2018). Achievement and response of students at favorite junior high schools in Sukabumi on trends in international mathematics and science study (TIMSS) questions. Biosfer: Jurnal Pendidikan Biologi, 11(2), 126133. https://doi.org/https://doi.org/10.21009/biosferjpb.v11n2.126-133

Tanujaya, B., Mumu, J., \& Margono, G. (2017). The Relationship between Higher Order Thinking Skills and Academic Performance of Student in Mathematics Instruction. International Education Studies, 10(11), 78-85. https://doi.org/10.5539/ies.v10n11p78

Truelove, H. B., \& Gillis, A. J. (2018). Perception of pro-environmental behavior. Global Environmental Change, 49(February), 175-185. https://doi.org/10.1016/j.gloenvcha.2018.02.009

Unal, A., \& Karakuş, M. A. (2016). Interacting Science through Web Quests. Universal Journal of Educational Research, 4(7), 1595-1600. https://doi.org/10.13189/ujer.2016.040712

Urbani, J. M., Truesdell, E., Urbani, J. M., Roshandel, S., Michaels, R., \& Truesdell, E. (2017). Developing and Modeling 21stCentury Skills with Preservice Teachers. Teacher Education Quarterly, 44(4), 27-51.

Vicente-Molina, M. A., Fernández-Sainz, A., \& Izagirre-Olaizola, J. (2018). Does gender make a difference in proenvironmental behavior? The case of the Basque Country University students. Journal of Cleaner Production, 176, 89-98. https://doi.org/10.1016/j.jclepro.2017.12.079

Vidergor, H. E., \& Krupnik-Gottlieb, M. (2015). High order thinking, problem based and project based learning in blended learning environments. In Applied Practice for Educators of Gifted and Able Learners (pp. 217-232). https://doi.org/10.1007/978-94-6300-004-8_11

Vijayaratnam, P. (2012). Developing Higher Order Thinking Skills and Team Commitment via Group Problem Solving: A Bridge to the Real World. Procedia - Social and Behavioral Sciences, 66, 53-63. https://doi.org/10.1016/j.sbspro.2012.11.247

Wall, T. F. (2015). The Transferability of Higher Order Cognitive Skills. Procedia - Social and Behavioral Sciences, 174, 233238. https://doi.org/10.1016/j.sbspro.2015.01.652

Weninger, C. (2018). Problematising the notion of "authentic school learning": insights from student perspectives on media/literacy education. Research Papers in Education, 33(2), 239-254.https://doi.org/10.1080/02671522.2017.1286683

Widiana, I. W., Jampel, N., \& Jampel, I. N. (2016). Improving Students' Creative Thinking and Achievement through The Implementation of Multiple Intelligence Approach with Mind Mapping. International Journal of Evaluation and Research in Education (IJERE), 5(3), 246-254.

Wiener-Ogilvie, S., Bennison, J., \& Smith, V. (2014). General practice training environment and its impact on preparedness. Education for Primary Care, 25(1), 8-17. https://doi.org/10.1080/14739879.2014.11494236

Yang, C.-M. (2018). Applying Design Thinking as a Method for Teaching Packaging Design. Journal of Education and Learning, 7(5), 52-61. https://doi.org/10.5539/jel.v7n5p52

Yeung, S. yin S. (2015). Conception of teaching higher order thinking: perspectives of Chinese teachers in Hong Kong. Curriculum Journal, 26(4), 553-578. https://doi.org/10.1080/09585176.2015.1053818

Yusop, F. D., \& Sumari, M. (2013). The Use of Social Media Technologies among Malaysian Youth. Procedia - Social and Behavioral Sciences, 103, 1204-1209. https://doi.org/10.1016/j.sbspro.2013.10.448

Zhou, Q., Lee, C. S., \& Sin, S. C. J. (2017). Using social media in formal learning: Investigating learning strategies and satisfaction. Proceedings of the Association for Information Science and Technology, 54(1), 472-482. https://doi.org/10.1002/pra2.2017.14505401051 